\title{
Influence of anthropometry on meat-packing plant workers: an approach to the shoulder joint
}

\author{
Pedro Ferreira Reis ${ }^{\mathrm{a}, \mathrm{b}, *}$, Luis Sérgio Peres ${ }^{\mathrm{c}}$, Adriana Seára Tirloni ${ }^{\mathrm{a}}$, Diogo Cunha dos Reis ${ }^{\mathrm{d}}$, Jansen \\ Atier Estrázulas ${ }^{\mathrm{e}}$, Mateus Rossato ${ }^{\mathrm{f}}$ and Antônio Renato Pereira Moro ${ }^{\mathrm{a}, \mathrm{d}, \mathrm{g}}$ \\ a Programa de Pós-Graduação em Engenharia de Produção, Universidade Federal de Santa Catarina, SC, Brazil \\ ${ }^{\mathrm{b}}$ Instituto de Ensino Superior de Foz do Iguaçu, PR, Brazil \\ ${ }^{\mathrm{C}}$ Universidade do Oeste do Paraná, PR, Brazil \\ ${ }^{\mathrm{d}}$ Programa de Pós-Graduação em Educação Física, Universidade Federal de Santa Catarina, SC, Brazil \\ ${ }^{e}$ Universidado Estado do Amazonas, AM, Brasil \\ ${ }^{f}$ Universidade Federal do Amazonas, AM, Brasil \\ ${ }^{g}$ Departamento de Educação Física, Universidade Federal de Santa Catarina, SC, Brazil
}

\begin{abstract}
This study was conducted with 90 poultry slaughterhouse workers, which perform the function of removing chicken parts from the conveyor belt, and sample was composed of 66 women ( $33.5 \pm 6.5$ years) and 24 men ( $35.7 \pm 7.2$ years), aiming to analyze the influence of anthropometry in the shoulder joint of these workers. Body discomfort was evaluated by a human body diagram, being applied at the end of the work shift. The anthropometric measurement of shoulder was performed by measuring the height of the acromion process, being compared with the height of the conveyor belt. Analysis of the results was performed by descriptive statistics, mean, standard deviation, percentage and percentiles $5 \%, 50 \%$ and $95 \%$. It was found that the height of the conveyor belt was 1.74 meters, while the average shoulder height of workers was 1.38 meters for percentile $5 \%, 1.41$ meters for percentile $50 \%$ and 1.65 meters for percentile $95 \%$. The discomfort regions were shoulder $45 \%$, neck $29 \%$, column $26 \%$, arms $23 \%$, and wrists and hand $20 \%$. The upper limb assessment was performed with percentile $5 \%$ through the Rapid Upper Limb Assessment method, resulting in a final score $>7$, indicating the need for adjustments of the work organization. It was concluded that the workplace does not meet the workers' anthropometric characteristics, mainly affecting the shoulder joint, and correction ergonomics becomes necessary so that the workers involved in this study can perform their functions with health, comfort and safety.
\end{abstract}

Keywords: Ergonomics, repetitive tasks, biomechanics

\section{Introduction}

In contemporary world, a great technological breakthrough has been observed, but unfortunately, some sectors need to advance in the ergonomics field. Thus, it is clear that the agribusiness sector, in special meat-packing plants, although under development in recent years, still has much to progress, since organizational, anthropometric, psychosocial and environmental concerns should be considered, which contribute to the development of occupational diseases of workers [10,23]. During the work activities of meat-packing plant employees, various activi- ties are undertaken, which use the shoulder joint with a significant frequency and mostly with inadequate posture. Anthropometry is the science that studies the anatomical structures, providing measurements of the human body [30]. In ergonomics, anthropometry plays an important role, since a poorly structured design in anthropometrical terms contributes to the illness of the worker, especially when this structure is designed for the average person, because the smallest (percentile 5\%) and highest ones (percentile 95\%) will be harmed [23]. In this sense, [13] reported that the shoulder joint is the most flexible of the human body, providing conditions to perform move-

\footnotetext{
* Corresponding author: Pedro Ferreira Reis, Instituto de Ensino Superior de Foz do Iguaçu, Pr, Brazil - Universidade Federal de Santa Catarina - Programa de Pós Graduação em Engenharia de Produção - Laboratório de Biomecânica - Campus Universitário, Trindade, Florianópolis, SC, Brasil. CEP: 88040-970; Tel. (55) 48-37218530. E-mail: ergoreis@hotmail.com
} 
ments with significant amplitude, but demands beyond its functional capacity may compromise its integrity. However, all extreme movements of the shoulder can only be done rarely and against little resistance, otherwise, it might suffer from overload that probably will lead to injury [12]. It is known that one of the most overloaded structures is the supraspinatus muscle, which when contracted causes humeral joint discomfort, impairing the mobility of this region [23]. Thus, when it remains statically for a long time with arm away, it will also develop a significant load on tendons and ligaments [28].

In this sense, it is important to protect all body joints, especially the shoulder joint. The wide variety of shoulder movements by one hand favors mobility, but on the other, when the physiological limits are not respected and labor activities are held in poor ergonomic conditions, these activities can significantly compromise the health of workers, in particular poultry slaughterhouse workers, who have a considerable use of this joint [5]. This author also warns that tasks performed with arms up compromise the integrity of this joint. Thus, preventing inflammation of the synovial bursa becomes critical to the health of workers so that the tendons of the supraspinatus and long head of the biceps brachial muscles can perform their functions without hindrance at the acromial region, and it is worth mentioning that bursa play a vital role in nourishing the muscles, mainly the muscles of the rotator cuff $[1,22]$. In this way, this study contributes to slaughterhouse professionals, preventing important pathologies such as the shoulder impingement syndrome, and tendinitis of the supraspinatus, which is caused when the shoulder protrudes forward with arms up and tendinitis of the long portion of the biceps, which is caused by permanence of wrist flexion with pronation of the forearm and mainly by the arm abduction, which is worsened when the arm is suspended without being supported [1].

Ergonomics is defined as the adaptation of work to the worker, where knowledge on psychology, anatomy and physiology contribute to improving the relationship between man, equipment, tools and environment, studying the fundamental criteria to adapt the workplace to human characteristics through theories, principles, methods and data that can provide a healthy, comfortable and safe work environment [23].

The existence of ergonomic risk factors in the workplace has a strong relationship with the emergence of musculoskeletal diseases. Thus, it is necessary to verify the anatomical region affected, and factors such as effort duration and intensity, work cycle, existence of recovery breaks and gender involved should be considered [12,17,23].

The ideal ergonomic environment should be built before being used, in accordance with the characteristics of each individual worker. In this sense, anthropometry describes the quantitative differences of measures of the human body, providing support for ergonomics to fit workplaces [14].

Technological changes introduced in the production line have enabled organizations to increase productivity and therefore profits, but brought consequences to the health of workers, which can be perceived in their physical, psychological and social sphere [21]. The emergence of new diseases related to changes made to the world of work has been evidenced in scientific productions in recent decades. Therefore, it is up to ergonomics to show ways for the improvement of the quality of life of these workers [12,17,23,25,36].

The shoulder has a complex joint that provides the greatest mobility among the joints of the human body, and due to this wide mobility, this joint is subject to various injuries, especially when submitted to repetitive and impacting tasks [39], and further exams are needed for a more precise evaluation of the affected tendon [24].

In the industrial environment, the shoulder impingement syndrome is the most common injury in the shoulder joint mainly caused by tasks performed in textile industries, supermarket operators, among other, which are highly repetitive tasks, causing pain, occupational injuries, removals and loss of productivity, often reaching functional disability, affecting mainly women [2]. It is likewise important to prevent workers from factors that contribute to the development of this syndrome, avoiding incorrect postures, repetition of movement and lifting arms above the shoulder level for long periods of time [7].

Vigorous and repeated movements of the upper limbs, with arms above shoulder level, will lead to clamping of the supraspinatus muscle tendon between the humeral head and coracoacromial ligament, resulting in ischemia, inflammation and pain; repetitiveness leads to calcification, which perpetuates inflammation, especially when rising arms above shoulder level [4,28].

Bursae are small pads of membrane with synovial fluid, which helps lubrication to facilitate movement, and when a tendon surrounded by the bursa moves with frequency, it irritates this membrane, producing an inflammatory process known as bursitis, causing 
pain and limited movement. Thus, it is important to adjust the height of the work plan, because if objects to be reached are too high, this height will need to be compensated with an increased flexion of the shoulders, which can cause pain at the level of shoulder blades, neck and shoulders, with worsening of the chronic disease, evolving into subacromial bursitis $[4,11]$.

Shoulder injuries can be classified as work-related illnesses due to working conditions that require awkward positions, repetitive movements, painful pace of work or unfavorable working conditions. Shoulder injuries, as well as other work-related musculoskeletal disorders are multifactorial, and may be due to the aggravation of a previous clinical condition; therefore providing favorable conditions within work organizations to prevent diseases of this joint is critical for the integrity of the worker's health [3]. Therefore, the aim of this study was to analyze the influence of anthropometry in biomechanics of the shoulder joint of a poultry slaughterhouse workers.

\section{Method}

\subsection{Participants}

This study was conducted with 90 poultry slaughterhouse workers, which perform the function of removing chicken parts from the conveyor belt, and sample was composed of 66 women $(33.5 \pm 6.5$ years) and 24 men ( $35.7 \pm 7.2$ years), aiming to analyze the influence of anthropometry in the shoulder joint of these workers. The procedures were approved by the local Committee for Ethics in Research with Human Subjects, according to the Declaration of Helsinki.

\subsection{Instruments}

Physical discomfort was evaluated using the human body diagram, being applied at the end of the work shift [16].

The anthropometric measurement of the shoulder was performed measuring the height from the acromial process (shoulder) to the ground [33]. The shoulder height was measured using a stadiometer, Cardiomed model, measuring from $40 \mathrm{~cm}$ to $220 \mathrm{~cm}$ in an erect position with arms extended downward, feet together against the apparatus and look at the Frankfurt plane. The ergonomic risk in the workplace was assessed by the RULA method - Rapid Upper
Limb Assessment [29], which evaluates the biomechanics of arms, forearms, wrists, neck, trunk and legs, using scores ranging from 1 to 7 , where values equal to or greater than 7 indicate that the workplace is not suited to the physiological characteristics of workers, and additional values such as intensity, strength and presence of breaks can also be observed (Table 1).

Table 1

Measures taken according to the final score of the Rapid Upper Limb Assessment method - Source: [29]

\begin{tabular}{|c|c|l|}
\hline $\begin{array}{c}\text { Level of } \\
\text { action }\end{array}$ & Values & \multicolumn{1}{|c|}{ Description } \\
\hline 1 & $1-2$ & $\begin{array}{l}\text { Stable posture, if not kept or repeated } \\
\text { for long periods of time. }\end{array}$ \\
\hline 2 & $3-4$ & $\begin{array}{l}\text { Indicate need for more detailed as- } \\
\text { sessment and changes may be required }\end{array}$ \\
\hline 3 & $5-6$ & $\begin{array}{l}\text { Indicate that assessment and changes } \\
\text { must occur soon }\end{array}$ \\
\hline 4 & $\geq 7$ & $\begin{array}{l}\text { Indicate the need to change imme- } \\
\text { diately }\end{array}$ \\
\hline
\end{tabular}

\subsection{Data Analysis}

The analysis of results was performed by descriptive statistics, mean, standard deviation, percentage and percentiles 5\%, 50\% and 95\% [3].

\section{Results}

It was verified that the height of the conveyor belt was 1.74 meters, and the workers' average shoulder height was 1.38 meters for percentile $5 \%, 1.41$ meters for percentile $50 \%$ and 1.65 meters for percentile $95 \%$. The discomfort regions were shoulder $45 \%$, neck $29 \%$, spine $26 \%$, arms $23 \%$, wrists and hand $20 \%$, confirming that for these workers, the most affected joint is the shoulder. Thus, this workplace can develop pathologies at the shoulder joint (Figure $1)$.

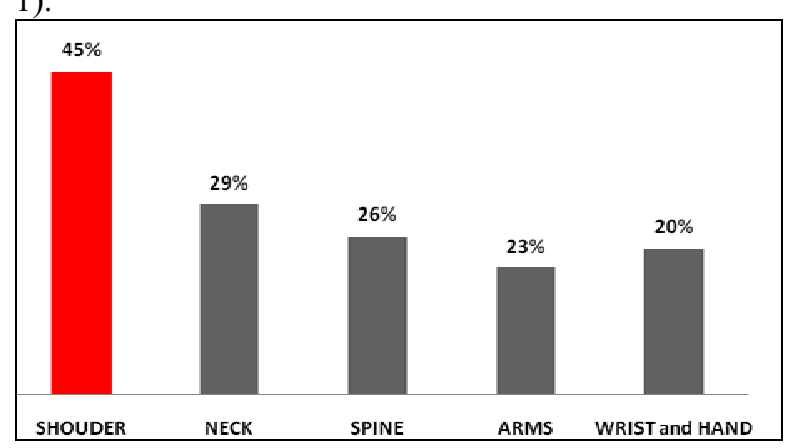

Fig. 1 - Discomfort percentage in joints 
In this study we found that many workers adopt incorrect postures according to the dimensional characteristics of the work equipment. Being satisfied that the workers included in the $5 \%$ percentile mostly women, are most affected (Figure 2).

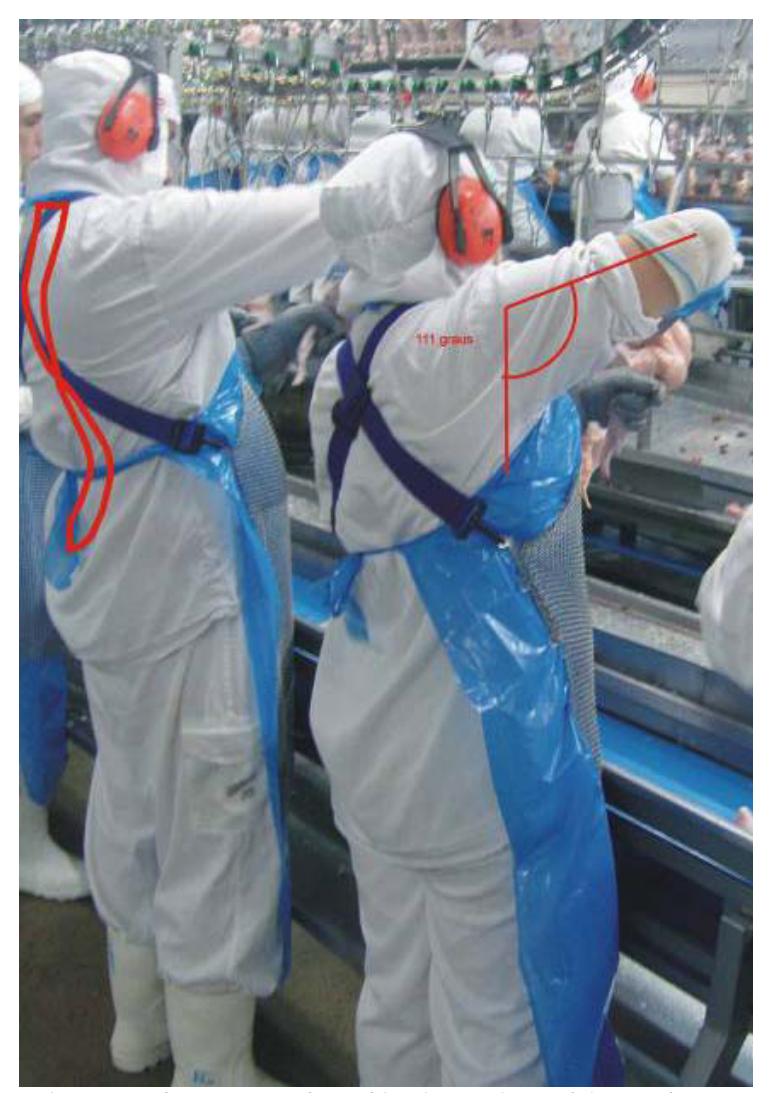

Fig. 2 - Body position adopted by the workers of the production line

The assessment of the workplace was performed using the Rapid Upper Limb Assessment method [29], using percentile 5\%. The assessment of the workplace using the Rapid Upper Limb Assessment method [29], carried out with percentile 5\%, showed a value $>7$, indicating the need for an immediate investigation in the organization of this workplace.

\section{Discussion}

Problems related to women's health in relation to musculoskeletal disorders have shown increasing levels, considerably impairing the quality of life in this population [35].
Shoulder injuries cause not only discomfort and pain but also provide reduction of the joint mobility, negatively affecting the functionality of the upper limb, affecting the work and daily life activities, reducing the quality of life of affected people, representing a major social and economic problem, given the high cost of treatment for recovery $[4,19,21,31]$.

Musculoskeletal problems arising from poorly organized work environments are concerning, as they lead to the appearance of occupational diseases with negative economic and social repercussions both for companies and for government, and especially for the family. Thus, providing an ergonomic workplace is of fundamental importance for companies due to the loss of employees, and for the government, which should provide the payment of welfare benefits for treatment and rehabilitation [20,41].

Anthropometrical data of a population are a crucial tool for ergonomics, providing information needed to size tools, machinery, equipment and workplaces, whether with static or dynamic posture, in standing or sitting position, in order to verify the adequacy of the task to the anthropometric characteristics of workers, according to criteria established by ergonomics, so that the task performed does not cause the appearance of diseases $[12,18]$.

Importantly, the collection of anthropometric data from populations of workers is needed throughout the production process, where man $\mathrm{x}$ machine interaction is necessary. In this sense, work organizations should be warned that the designing of workplaces should be done individually in order to meet the characteristics of each subject. Unfortunately, in function of the high costs, anthropometric surveys are conducted to meet the majority of the population and in some cases to meet percentiles 5\%, 50\% and 95\% [17].

Raising the arms above the shoulder level will lead to mechanical compression of tendons of rotator cuff and subacromial bursa muscles and tendons of the long head biceps muscles, pressing the anterior surface of the acromion and corocoacromial ligament [4,7-9,13,27,31,34,38].

Several muscles contribute to the stability of the shoulder joint, and this set of muscles is called the rotator cuff, composed of four muscles and tendons (supraspinatus, infra-spinal, subscapularis and teres minor), which originate in the scapula and insert on the tuberosities of the humerus, being responsible for the movement and stability of the glenohumeral joint $[4,6,31]$. Thus, the excessive use these muscles can contribute to the formation of calcium deposits 
within the tendon, mainly affecting the tendon of the supraspinatus muscle [37].

In today's world, the need for large production contributes to the establishment of workplaces in the form of production line with conveyor belts that are not designed to meet the heterogeneous characteristics of workers. Thus, it is important to emphasize that a workplace poorly sized will raise the production costs and undermine the motivation of workers due to unnecessary energy expenditure and fatigue stemming from incorrect postures provides discomfort to the worker, many times leading to the occurrence of diseases [36].

Designing a work environment for the average person is aimed at comforting most users; however, when men and women perform the same job, this will affect their health due to the significant difference of anthropometric measurements between men and women, and only a small number of workers will be benefited [36]. In this sense, the importance of anthropometry for ergonomics becomes evident, so that workers can perform their activities with maximum comfort and efficiency $[12,17,23,36]$.

Diseases arising from repetitive movements, known as RSI (Repeated Strain Injury) affect the muscular system, where joints, ligaments, tendons and nerves are the most affected, especially when the worker does not recover or rest. In this sense, repetitive work with arms above shoulder level provides significant contractions of the upper limb joints, especially shoulder, leading to shoulder impingement syndrome [11-12,19]. Thus, the rotator cuff can be affected by tendinopathies, mainly bursitis and calcific tendonitis, with narrowing of the subacromial space, which can have mechanical, biological or multifactorial origin, due to incorrect postures of the shoulder joint [26]. To keep the shoulder joint from being vulnerable to illness, the work plan cannot be above the worker's shoulder level, thus avoiding overloading in this joint [25]. Therefore, repetitive movements should be avoided, since the performance of repetitive and forceful movements with arms raised above the shoulder level will compromise the supraspinatus muscle, which is responsible for the arm abduction, hampering its mobility [15].

Thus, it was found that the workplace is inadequate and should be investigated immediately, and the shoulder joint was the most frequently exposed to occupational risk, since $80 \%$ of workers remained with their arms raised above the shoulder level, which caused injuries and pain in this region, corroborating the report of several authors, who warn that lifting the arms above the shoulder level provides unnecessary wearing of the humeral joint [4,7-9,11-13,19,27-28,31,34,38].

It could be concluded that the job does not meet the workers' anthropometric characteristics. Thus, it is worth mentioning that the shoulder joint is the most affected, since the poor design of the workplace provides a lifting of the arm above the shoulder line, contributing to a physiological wear of this joint, leading to loss of production and to several diseases. According to reports from [28], the lifting of the arm above the shoulder line in addition to repeated movements will contribute to ischemia, inflammation and pain, leading the worker to the loss of the labor function. Thus, it appears that correction ergonomics is necessary for these workers to perform their duties with health, comfort and safety.

It was found that workplaces should be suited to anthropometric measurements of workers. In addition, recovery breaks and job rotation should be included during the work shift. Finally, it is important that men and women do not develop repetitive tasks with the same intensity and volume in function of their anthropometric and physiological differences.

\section{References}

[1] J.R. Andrews, G.L. Harrelson and K.E.Wilk, Reabilitação física das lesões desportivas, (2 ed.), Guanabara Koogan, Rio de Janeiro, 2000.

[2] C.H. Barbieri, N. Mazer and J.H. Calil, Shoulder impingement syndrome: comparative study of the results of surgical treatment by Watson and Neer techniques, Revista Brasileira de Ortopedia 30 (1995), 753-760.

[3] M.V.G. Barros and R.S. Reis, Análise de dados em atividade física e saúde: demonstrando a utilização do SPSS, (1 ed.), Midiograf, Londrina, 2003.

[4] P.M. Bongers, The cost of shoulder pain at work, British Medical Journal 322 (2001), 72-78.

[5] K.I. Brox, Shoulder pain, Best Pratice \& Research Rheumatology 17 (2003), 33-56.

[6] J.R. Bytomski and D.Black, Conservative treatment of rotator cuff injuries, Journal of Surgical Orthopaedic Advances 15 (2006), 126-131.

[7] P.R. Camargo, et al., Pain in workers with shoulder impingement syndrome: an assessment using the DASH and McGill pain questionnaires, Revista Brasileira de Fisioterapia 11 (2007), 161-167.

[8] P.R. Camargo, et al., Bilateral deWcits in muscle contraction parameters during shoulder scaption in patients with unilateral subacromial impingement syndrome, Isokinetics and Exercise Science 16 (2008), 93-99.

[9] A.B. Castro, Shoulder Impingement Syndrome, Diagnosis and Management, Revista dor 10 (2009), 174-179.

[10]L.G. Chiavegato Filho and J.R.Pereira, Work related osteomuscular diseases: multifactorial etiology and explanatory models, Interface - Comunicação, Saúde, Educação 8 (2004), 149-62. 
[11]H.G. Coury, Trabalhando Sentado, Ufscar, São Carlos, 1995.

[12]H.A. Couto, Ergonomia Aplicada ao Trabalho: Conteúdo Básico - Guia Prático, Ergo Ltda, Belo Horizonte, 2007.

[13]E. Criscuolo, S.S. Pinto, G. Puglise and C. Oliveira, Torque of the rotator muscles of the shoulder after Bristow's procedure, Revista Brasileira de Ortopedia 35 (2002), 452-456.

[14]J. Dul and B.Weerdmeester, Ergonômica Prática, Traduzido por Itiro Iida, (2 ed.), Edgard Blucher, São Paulo, 2004.

[15]D. Dutra, E.J. Stecca, P.F.R. Pereira and C.P.C.M. Siqueira, Shoulder pain prevalence in elementary teachers of the municipal schools of Umuarama - PR in the year of 2004 Arquivos de Ciências da Saúde da UNIPAR 9 (2005), 79-84.

[16] J.A.E. Eklund and E.N. Corlett, Experimental and biomechanical analysis of seating, In: N. Corlett, J. Wilson and I. Manenica (Eds.), The Ergonomics of Working Postures, Taylor and Francis Ltd, London, 1986, pp. 319-330.

[17]H. C. Fernandes, et al., Ergonomic evaluation of the operator cabin of a forest tractor, Revista Ceres 57 (2010), 307-314.

[18] M.J.M. Fonseca, E. Faerstein, D. Chor, and C.S. Lopes, Validity of self-reported weight and height and the body mass index within the "Pró-saúde" study, Revista de Saúde Pública 38 (2004), 392-398.

[19] W.J. Grooten, et. al.,The influence of work-related exposures on the prognosis of neck/ shoulder pain, European Spine Journal 16 (2007), 2083-2091.

[20] M. Hagberg, E.W. Tornqvist and A. Toomingas, Selfreported reduced productivity due to musculoskeletal symptoms: associations with workplace and individual factors among white-collar computer users, Journal Occupational Rehabilitation 12 (2002), 151-162.

[21] W.E. Hooftman, What makes men and women with musculoskeletal complaints decide they are too sick to work? Scandinavian Journal of Work, Environment \& Health 34 (2008), 107-112.

[22]A. I. Horn, et al., Kinesiotherapy prevents shoulder pain in hemiplegic/paretic patients on sub-acute stage post-stroke, Arquivos de Neuropsiquiatria 61 (2003), 768-771.

[23]I. Iida, Ergonomia: Projeto e Produção, Edgard Blucher, São Paulo, 2005, pp.614.

[24]H.A. Kim, S.H. Kim and Y.I. Seo, Ultrasonographic fi ndings of painful shoulders and correlation between physical examination and ultrasonographic rotator cufftear, Modern Rheumatology 17 (2007), 213-219.

[25] K.H.E. Kroemer and E. Grandejean, Manual de Ergonomia: Adaptando o Trabalho ao Homem, Bookman, Porto Alegre, 2005, pp.327.

[26]O. Lech and A. Severo, Ombro e cotovelo, In: S. Hebert, R. Xavier, A.G. Pardini Junior and T.E.P. Barros Filho (eds.), Ortopedia e traumatologia, (3 ed.), Artmed, São Paulo, 2003, pp. $185-237$.
[27]P.M. Ludewig and J.F. Reynolds, The association of scapular kinematics and glenohumeral joints pathologies, Journal of Orthopaedic \& Sports Physical Therapy 39 (2009), 90-104.

[28]D.J. Magee and N.G. Oliveira, Avaliação Músculo esquelética, (4 ed.), Manole, Barueri, 2005, pp.208.

[29] L. McAtamney and E.N. Corlett, RULA: a survey method for the investigation of work-related upper limb disorders, Applied Ergonomics 24 (1993), 91-99.

[30] T.N. Menezes and M.F.N. Marucci, Antropometria de idosos residentes em instituições geriátricas, Fortaleza, CE, Revista de Saúde Pública 39 (2005), 169-175.

[31] S.J. Mousavi, et al., Cultural adaptation and validation of the Persian version of the Disabilities of the Arm, Shoulder and Hand (DASH) outcome measure, Clinical Rehabilitation 22 (2008), 749-757.

[32]N.T. Murofuse and M.H.P. Marziale, Diseases of the osteomuscular system in nursing workers, Revista LatinoAmericana de Enfermagem 13 (2005), 364-373.

[33]E.L. Petroski, Antropometria: técnicas e padronizações, (1 ed.), Pallotti, Santa Maria, 1999, pp.2008.

[34] V. Phadke, P.R. Camargo and P.M. Ludewig, Scapular and rotator cuff muscle function during arm elevation: a review of normal function and alterations with shoulder impingement, Revista Brasileira de Fisioterapia 13 (2009), 1-9.

[35]L. Punnett, and D.H. Wegman, Work-related musculoskeletal disorders: the epidemiologic evidence and the debate, Journal of Electromyography Kinesiology 14 (2004), 13-23.

[36]C.R. Rodriguez-Añez, Anthropometry and it application in ergonomics, Revista Brasileira de Cineantropometria Desempenho Humano 3 (2001), 102-108.

[37]M. Sabeti, et al., A comparison of two different treatments with navigated extracorporeal shock-wave therapy for calcifying tendinitis - a randomized controlled trial, Wien Klin Wochenschr 119 (2007), 124-128.

[38] L.J. Soslowsk, et al., Rotator cuff tendinosis in an animal model: Role of extrinsic and overuse factors, Annals of Biomedical Engineering 30 (2002), 1057-1063.

[39]A.P. Souza, et al., The effects of different resources fototherapeutic on the pain in individuals bearers of Syndrome of the Impact of the shoulder, Fitness \& performance Journal 5 (2006), 355-342.

[40]E.L. Tavares and L.A. Anjos, Anthropometric profile of the elderly Brazilian population: results of the National Health and Nutrition Survey, Cadernos de Saúde Pública 15 (1999), 759-768.

[41]A. Vitta, R.S. Bertaglia and C.R. Padovani, Effects of two educational programs on musculoskeletal symptoms in office workers, Revista Brasileira de Fisioterapia 12 (2008), 20-25. 